\title{
Experimental Studies on the Structural Strength of Pumping Concrete in Winter
}

\author{
SHENG Chang ${ }^{1, *}$, ZHOU Qunmei ${ }^{1}$, LING Shangzhuan ${ }^{2}$ \\ ${ }^{1}$ Jinhua Polytechnic, Zhejiang Jinhua 321007, China \\ ${ }^{2}$ Jinhua Xincheng Testing Co., Ltd, Zhejiang, Jinhua, 321018, China
}

\begin{abstract}
The strength growth of concrete depends on the hydration reaction of cement. Curing temperature and humidity are important conditions to determine the hydration rate of cement. In this paper, rebound method is used to detect the structural strength of pumping commercial concrete in winter construction in Jinhua. The relationship between temperature, rebound value and compressive strength value is analyzed based on the concrete strength detection data. At the same time, some effective measures are put forward to solve the problems in winter construction.
\end{abstract}

\section{Introduction}

With the rapid development of the construction industry, concrete has become the most important structural material in contemporary construction engineering, and its quality directly affects the quality and safety of the whole building structure. Therefore, the detection and evaluation of concrete strength, as the main part of engineering construction quality control, has become an important research topic in today's construction engineering technology. The strength growth of concrete is restricted by many factors. When the concrete mix ratio and construction technology are determined, the curing temperature and age will become the key factors of the concrete strength growth ${ }^{[1]}$.

The Code for quality acceptance of concrete structure construction stipulates that the same condition curing specimen method should be used for the inspection of concrete strength. When the same condition curing specimen strength is not obtained or the same condition curing specimen strength does not meet the requirements, rebound methods or rebound and core specimen correction method should be used for inspection. In winter construction, the equivalent curing age of concrete strength inspection can be taken as the corresponding age when the daily average temperature reaches $600^{\circ} \mathrm{C} \cdot \mathrm{d}$, and should not be less than 14 days. The age when the daily average temperature is $0^{\circ} \mathrm{C}$ or below is not included ${ }^{[2]}$.

Jinhua Municipal construction administrative department issued the "Interim provisions on sampling inspection of concrete structure construction quality in Jinhua area" in August 2016. The Interim provisions specifies that reinforced concrete construction projects include new construction, expansion and reconstruction projects. These projects shall be subject to sampling inspection of structural quality before the acceptance of foundation and main structure engineering. The results can be used as an important basis to evaluate the quality of engineering structure. The rebound method is preferred for the upper structure, and the coring method is preferred for the foundation. When the rebound method is used to test the concrete strength, the first test day is when the daily average temperature add up $600^{\circ} \mathrm{C} \cdot \mathrm{d}$ (except for those with special design requirements). If the first test fails, the rebound coring method shall be used to retest within five working days ${ }^{[3]}$.

In this paper, the strength test data of concrete entity in winter construction are analyzed, combined with the actual situation of concrete strength test of structural entity in Jinhua area. Then, the numerical relationship between rebound value and compressive strength value of concrete strength detection is analyzed. At the same time, the problems existing in detection application are discussed. The problems that should be paid attention to in engineering construction and engineering detection under low temperature are analyzed, and some effective technical solutions are put forward.

\section{Experimental}

\subsection{Experimental temperature}

The annual temperature statistics of Jinhua are shown in Figure 1 in recent five years according to the daily average temperature data provided by Jinhua Meteorological Bureau. In Fig. 1a, statistical chart of monthly average temperature of Jinhua in recent five years. In Fig. 1b, statistical chart of daily average temperature from January to February of Jinhua in recent years.

According to the temperature data, taking 2016 as an example, it can be concluded that the daily average temperature was lower than $5^{\circ} \mathrm{C}$ for 10 days, $5^{\circ} \mathrm{C} \sim 10^{\circ} \mathrm{C}$ for 17 days and $10{ }^{\circ} \mathrm{C} \sim 15^{\circ} \mathrm{C}$ for 4 days in January; in

* Corresponding author: ykzqm@126.com 
February, the daily average temperature was lower than $5^{\circ} \mathrm{C}$ for 5 days, higher than $10{ }^{\circ} \mathrm{C}$ for 12 days, which was warmer than that in January; the daily average temperature was lower than $5{ }^{\circ} \mathrm{C}$ for 3 days, $5{ }^{\circ} \mathrm{C} \sim 10{ }^{\circ} \mathrm{C}$ for 9 days, $10{ }^{\circ} \mathrm{C} \sim 15{ }^{\circ} \mathrm{C}$ for 18 days in December. There are only two days in 2016 when the daily average temperature is lower than $0{ }^{\circ} \mathrm{C}$.

From the figure, we can see that the average daily temperature in Jinhua is negative in a few periods, and positive in most other periods. The monthly average temperature is between $5{ }^{\circ} \mathrm{C}$ and $10{ }^{\circ} \mathrm{C}$ in January, February and December; the monthly average temperature is between $10{ }^{\circ} \mathrm{C}$ and $15{ }^{\circ} \mathrm{C}$ in March and November. The temperature in Jinhua is at a low level for about five months of the year. So, $5{ }^{\circ} \mathrm{C}, 10{ }^{\circ} \mathrm{C}$ and $20^{\circ} \mathrm{C}$ is used as the experimental temperature.

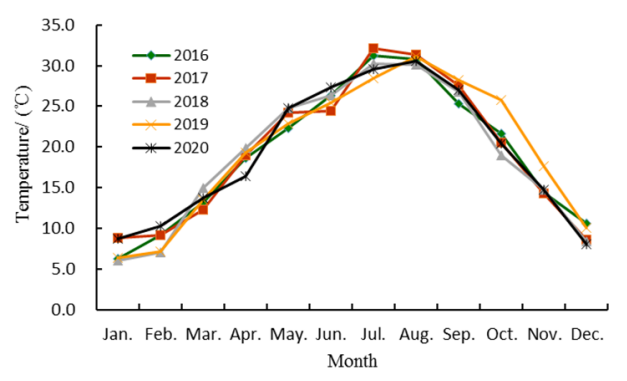

a. Monthly average temperature statistics

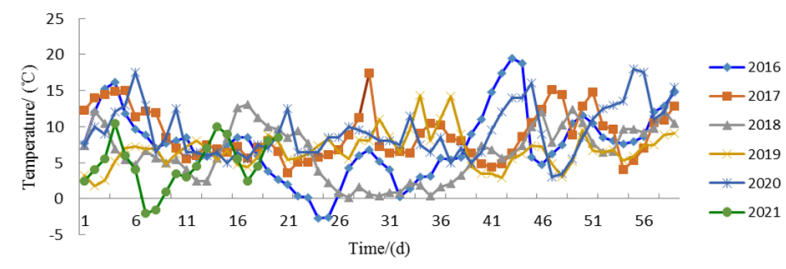

b. Statistical chart of daily average temperature from January to February

Fig.1. Temperature statistics of Jinhua in recent five years

\subsection{Experimental scheme}

The axial compressive strength of concrete at different ages under different temperatures of $5^{\circ} \mathrm{C}, 10^{\circ} \mathrm{C}$ and $20^{\circ} \mathrm{C}$ and the same condition curing of winter was studied in order to study the influence of Jinhua low temperature curing conditions on the strength performance of concrete. The control variable method was used in the test, and only the curing conditions were changed to obtain the rebound value and compressive strength value of the same batch of concrete at different ages of 3 days, 7 days, 14 days, 28 days and 60 days. The $20{ }^{\circ} \mathrm{C}$ test group was used as the control test under standard curing.

\section{2.1 Concrete sample making}

In this experiment, the concrete preparation refers to the pumping concrete of local common commercial concrete company, and the concrete mix proportion is shown in Table 1, C30 and C35 concrete are selected. The standard Cube Specimens of $150 \mathrm{~mm} \times 150 \mathrm{~mm} \times 150 \mathrm{~mm}$ are used. The low temperature curing equipment adopts high and low temperature damp heat test box, the standard curing equipment adopts constant temperature standard curing room, and the curing test block under the same conditions is placed in the outdoor shade. The concrete preparation refers to the pumping concrete of local common commercial concrete company, and the concrete mix proportion is shown in Table 1.

The concrete is mixed by a professional concrete mixer, and the Concrete sample is poured in the horizontal position. The surface shall be smoothed after being vibrated by the vibration table for $60 \mathrm{~s}$. The specimens were first watered and cured in the indoor (average temperature of $15^{\circ} \mathrm{C}$ within one day) for one day, and then sent to different temperature curing box, standard curing room and outdoor curing respectively after removing the formwork. After the specimens were cured to the specified age, the test was carried out. The test is carried out at room temperature based on the principle that the specimen is least affected by room temperature.

Table 1. concrete proportioning

\begin{tabular}{|c|c|c|c|c|}
\hline grade & $\begin{array}{c}\text { Cement } \\
\text { content } \\
\left(\mathrm{kg} / \mathrm{m}^{3}\right)\end{array}$ & $\begin{array}{c}\text { Mixing ratio } \\
\text { (cement: sand: breakstone: water: } \\
\text { fly ash: mineral powder })\end{array}$ & $\begin{array}{c}\text { Water } \\
\text { reducer } \\
\left(\mathrm{kg} / \mathrm{m}^{3}\right)\end{array}$ \\
\hline $\mathrm{C} 30$ & 280 & $1: 3.14: 3.07: 0.66: 0.18: 0.25$ & 7.8 \\
\hline $\mathrm{C} 35$ & 300 & $1: 3.00: 2.93: 0.62: 0.13: 0.27$ & 7.6 \\
\hline
\end{tabular}

\subsubsection{Testing}

The carbonation value of concrete test block, rebound value and compressive strength value of rebound nondestructive testing method are tested in this test.

Carbonization value $\mathrm{L}$ was determined by phenolphthalein reagent. The rebound value $\mathrm{R}$ is measured by a HT-225T integrated digital display rebound meter. When measuring the rebound value, wipe off the oil stains on the test block, place the two surfaces of the test block in contact with the side plate of the test mold between the upper and lower bearing plates of the press, and fix the test block with the press and a preload of $30 \mathrm{kN} \sim 50 \mathrm{kN}$. Then, the other corresponding side of the test block is selected to rebound, the axis of the rebound instrument is vertical to the side of the test block, the measuring points are evenly distributed in the measuring area, and the distance between two adjacent measuring points and the distance between the measuring points and the edge of the test block is generally not less than $30 \mathrm{~mm}$. A total of 16 rebound values were measured by 8 times of bouncing on a pair of corresponding test surfaces of the test block, 3 maximum values and 3 minimum values were eliminated, and the remaining 10 rebound values were taken as the average value, that is, the average rebound value $\mathrm{R}$ of the test block.

The compressive strength of concrete is measured by a YAW-3000 microcomputer controlled electro-hydraulic servo pressure testing machine. After the rebound test is completed, unload the test block first, place the rebound value surface of the test block between the upper and lower bearing plates of the press, and pressurize continuously and evenly at the speed of $6 \mathrm{kN} \sim 10 \mathrm{kN}$ per second until the test block is damaged, so as to obtain the 
compressive strength value of concrete.

\section{Result and Discuddion}

The strength growth of concrete depends on the hydration reaction of cement, and the curing temperature and humidity are important conditions to determine the hydration rate of cement. In the case of the same water cement ratio, the reduction of temperature will slow down the hydration reaction rate of cement. Continuous lowtemperature hydration environment can significantly reduce the hydration heat of cement hydration at each age, reduce the degree of hydration at each age, thus limiting the growth of concrete strength at each age ${ }^{[4,5]}$.

\subsection{Development law of concrete strength with days under different curing temperature}

The relationship between age and concrete compressive strength under different curing conditions is shown in Table 2. Comparing the compressive strength of concrete in the same age, we can see that the compressive strength of concrete will increase with the increase of curing temperature. Under the same curing condition, the compressive strength of concrete increases with the increase of age, but the increase is not obvious under the condition of low temperature curing. The growth of concrete strength is a process from fast to slow. Because of the continuous low temperature, the growth of concrete strength is obviously restricted by the environment.

Table 2. Relationship between age and compressive strength of concrete

\begin{tabular}{|c|c|c|c|c|c|}
\hline \multirow{4}{*}{ grade } & $\begin{array}{c}\text { Age } \\
/ \mathrm{d}\end{array}$ & $\begin{array}{c}\text { strength } \\
/ \mathrm{Mpa} \\
\left(5^{\circ} \mathrm{C}\right)\end{array}$ & $\begin{array}{c}\text { strength } \\
/ \mathrm{Mpa} \\
\left(10^{\circ} \mathrm{C}\right)\end{array}$ & $\begin{array}{c}\text { strength } \\
/ \mathrm{Mpa} \\
(\text { same } \\
\text { condition })\end{array}$ & $\begin{array}{c}\text { Strength } \\
/ \mathrm{Mpa} \\
\left(20^{\circ} \mathrm{C}\right)\end{array}$ \\
\hline \multirow{5}{*}{ C35 } & 7 & 24.7 & 22.4 & 24.9 & 30.0 \\
\cline { 2 - 6 } & 14 & 27.1 & 28.0 & 35.1 & 39.2 \\
\cline { 2 - 6 } & 28 & 29.3 & 31.4 & 38.2 & 42.9 \\
\cline { 2 - 6 } & 56 & 31.7 & 36.8 & 38.7 & - \\
\hline \multirow{5}{*}{ C30 } & 7 & 9.4 & 21.4 & 22.5 & 24.9 \\
\cline { 2 - 6 } & 14 & 17.5 & 28.3 & 27.1 & 36.1 \\
\cline { 2 - 6 } & 28 & 27.2 & 31.4 & 32.1 & 38.7 \\
\cline { 2 - 6 } & 56 & 30.3 & 35.7 & 37.8 & - \\
\hline
\end{tabular}

The growth curve of pumping concrete strength with age of two concrete strength grades is shown in Fig.2. In Fig. 2a, the concrete strength grades is C30. In Fig. 2b, the concrete strength grades is C35. It can be seen from the test that the two grades of pumping commercial concrete provided by the concrete company have different degrees of super strength phenomenon. The reason of super strength may be that the commercial concrete manufacturers are concerned about the unqualified concrete strength and intend to improve the mixing strength. The phenomenon of super strength caused by unreasonable acceptance is also common. The super strength of concrete can increase the production cost and waste resources, which is not conducive to the quality management of concrete. Blindly improving the strength of concrete construction will also lead to the increase of concrete shrinkage and the general cracking of cast-inplace structure. Therefore, in order to clarify the respective responsibilities of commercial concrete production units and construction maintenance units, the standard maintenance strength $f_{c u, o}$ and the structural strength $f_{c u, s}$ should be distinguished, so as to control the occurrence of blind super strength.
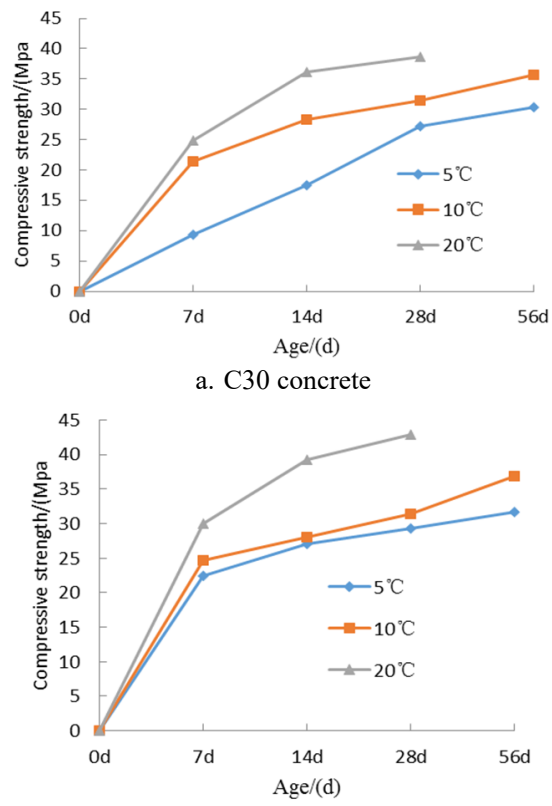

b. C35 concrete

Fig.2. Growth curve of pumping concrete strength with age

\subsection{Relationship between rebound value and compressive strength of concrete}

The relationship between age under low temperature curing (the curing temperature is $10^{\circ} \mathrm{C}$ ) and rebound value, compressive strength of concrete blocks is shown in Table 3. In the table, $f_{c u, 1}$ is the strength value inferred from national unified pumping concrete strength curve. $f_{c u, 2}$ is the strength value inferred from strength curve of macadam pumping concrete in Zhejiang Province. $f_{c u, 3}$ is the compressive strength of concrete measured by pressure testing machine

For concrete under non-standard curing conditions, the maturity of concrete can be calculated according to the following formula.

Concrete maturity $\mathrm{M}$ is as follows:

$$
M=\sum_{i=1}^{n} T_{i} \cdot \Delta t_{i}
$$

Where $\mathrm{M}\left({ }^{\circ} C \cdot d\right)$ is the maturity of concrete, $T_{i}\left({ }^{\circ} C\right)$ is the emperature in the time interval $\Delta t_{i}(d)$. 
Table 3. Relationship between age and rebound value, compressive strength of concrete block

\begin{tabular}{|c|c|c|c|c|c|c|c|}
\hline grade & $\begin{array}{c}\text { Age } \\
/ \mathrm{d}\end{array}$ & $\begin{array}{c}\mathrm{M} \\
/ \\
{ }^{\circ} \mathrm{C} \cdot d\end{array}$ & $\mathrm{R}$ & $\begin{array}{c}\mathrm{L} \\
/ \mathrm{mm}\end{array}$ & $\begin{array}{c}f_{c u, 1} \\
/ \mathrm{Mpa}\end{array}$ & $\begin{array}{c}f_{c u, 2} \\
/ \mathrm{Mpa}\end{array}$ & $\begin{array}{c}f_{c u, 3} \\
/ \mathrm{Mpa}\end{array}$ \\
\hline \multirow{5}{*}{$\mathrm{C} 30$} & 7 & 75 & - & - & - & - & 21.4 \\
\cline { 2 - 8 } & 14 & 145 & 32.0 & 0.5 & 28.0 & 31.0 & 28.3 \\
\cline { 2 - 8 } & 28 & 285 & 35.1 & 4.0 & 29.3 & 34.0 & 31.4 \\
\cline { 2 - 8 } & 56 & 565 & 36.0 & 4.5 & 35.4 & 38.1 & 35.7 \\
\hline \multirow{5}{*}{ C35 } & 7 & 75 & 21.0 & 0 & 12.7 & 15.5 & 22.4 \\
\cline { 2 - 8 } & 14 & 145 & 34.1 & 0.5 & 31.8 & 36.0 & 28.0 \\
\cline { 2 - 8 } & 28 & 285 & 35.7 & 4.0 & 30.2 & 35.0 & 31.4 \\
\cline { 2 - 8 } & 56 & 565 & 36.5 & 4.5 & 36.0 & 40.0 & 36.8 \\
\hline
\end{tabular}

Comparing the compressive strength value measured by uniaxial compression test and the compressive strength value inferred by rebound method under different curing conditions in Table 2, it is found that the growth law of concrete strength value is similar with the increase of age, which indicates that rebound method has certain feasibility and practicability in detecting concrete solid strength under low temperature environment. However, from the data in Table 3, we also find that the concrete strength values converted by different strength measurement curves are quite different, and they are also different from the strength values obtained by compression test.

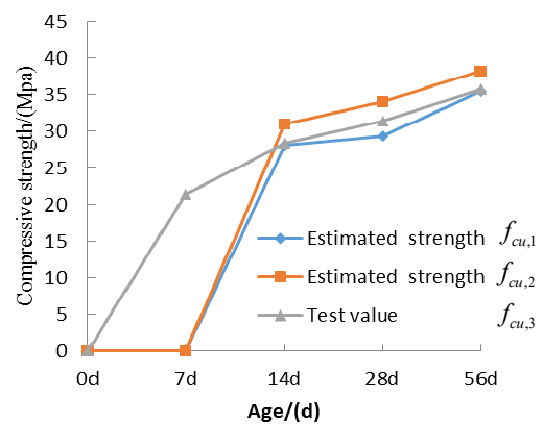

a. $\mathrm{C} 30$ concrete

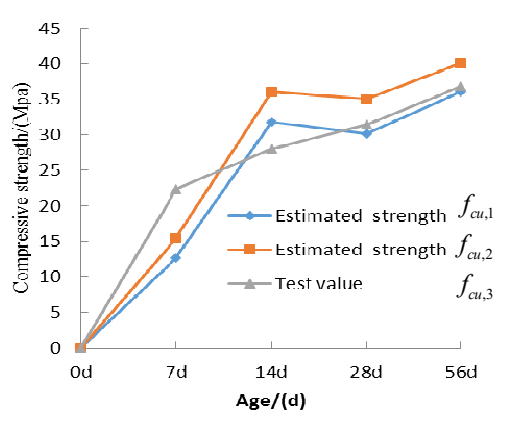

b. C35 concrete

Fig.3. Growth curve of concrete strength estimation value, pressure test value with age

In Figure 3, comparing the two concrete compressive strength values $\left(f_{c u, 1}\right.$ and $\left.f_{c u, 2}\right)$ inferred from the rebound value with the concrete compressive strength values $\left(f_{c u, 3}\right)$ measured by the pressure testing machine, the value of $f_{c u, 1}$ and $f_{c u, 2}$ is different from $f_{c u, 3}$. With the increase of age, the value of $f_{c u, 1}$ is closer to that of $f_{c u, 3}$. So, the strength value inferred from the national unified pumping concrete strength curve is closer to the structural strength of concrete.

Compared with the test results of reference 6 and other experts and scholars, the test data has some discreteness due to the short test time and small number test pieces. But the results are consistent with the analysis results of other scholars, which shows that the test data are reasonable ${ }^{[6,7]}$.

\subsection{Growth law of pumping concrete strength with maturity at low temperature}

The ratio of low temperature curing test block strength $f_{c u, t}$ to $28 \mathrm{~d}$ standard curing strength $f_{c u, o 28}$ can reflect the growth of concrete strength. According to the test data accumulated C30, C35 concrete maturity and concrete strength value established curve is shown in Figure 4.

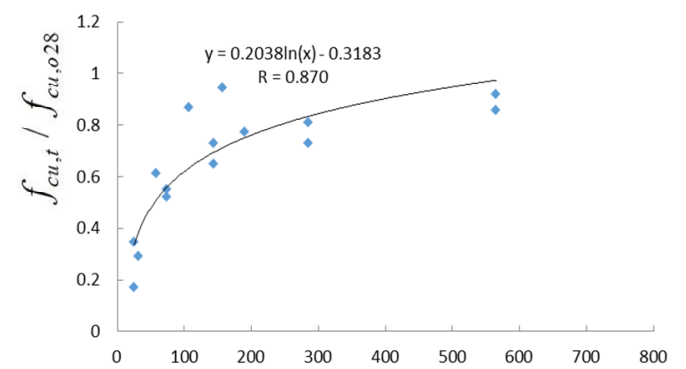

Fig.4. Growth curve of concrete strength and maturity

From the above curve, the growth law of concrete strength with maturity is obtained as follows:

$$
f_{c u, t} / f_{c u, o 28}=0.2038 \ln (M)-0.3183
$$

The correlation coefficient of the curve $\mathrm{R}$ is 0.870 . Therefore, there is a good correlation between the ratio $f_{c u, t} / f_{c u, o 28}$ and cumulative concrete maturity. For the concrete strength inferred from this curve, the cumulative maturity is $640{ }^{\circ} C \cdot d$ when the curing strength under the same condition reaches the $28 \mathrm{~d}$ strength of concrete standard curing. The temperature is close to $600^{\circ} \mathrm{C} \cdot d$, but there is a certain difference, which needs to be corrected by more test data.

\subsection{Measures of concrete structural strength detected by rebound method in winter}

Rebound method has the advantages of simple equipment, convenient operation and no damage to the components. The method is a widely used strength test method of concrete structure in Jinhua. However, there are many factors affecting the strength of concrete by rebound method, such as age, carbonation depth, different raw materials and mix proportion, molding process, curing method, environmental temperature, etc. In the technical 
specification of rebound method for testing concrete compressive strength, some measures are given for different influencing factors, such as the determination of carbonation depth, and the carbonation correction coefficient is introduced in the strength conversion of concrete measurement area, so as to avoid the hidden trouble caused by the high strength conversion value of rebound method to the engineering practice.

Different molding process such as pumping process will greatly affect the strength conversion value of rebound method. The national standard "technical specification for testing concrete compressive strength by rebound method" lists the strength conversion tables of concrete in testing area and pumping concrete in testing area. The strength conversion table of gravel pumping concrete and pebble pumping concrete are listed in the engineering construction standard of Zhejiang Province "technical specification for testing compressive strength of pumping concrete by rebound method". The compressive strength of concrete obtained from different strength conversion tables varies greatly. Therefore, the concrete forming process and raw materials should be clear in the application of rebound method. The application accuracy of these conversion tables should be further determined by experiments in Jinhua.

During winter construction, the curing temperature has a very important influence on the growth of concrete. When the temperature drops below $0{ }^{\circ} \mathrm{C}$, the water in the concrete freezes, and the hydration reaction of cement even stops, and the growth of concrete strength also stops. Therefore, certain construction measures must be taken to meet the conditions required by the cement hydration reaction in winter construction, so that the cement hydration reaction can proceed smoothly, and ensure that the concrete strength meets the design requirements. According to the reference 8, under the winter construction conditions of Tangshan, the concrete is mixed with antifreeze and some measures are taken to keep the concrete warm. The increase of concrete strength conforms to the law of logarithmic curve. The quantity of antifreeze and the effectiveness of thermal insulation measures for the strength growth of winter concrete also need further tests to prove in Jinhua.

\section{Conclusions}

The curing temperature and curing age of concrete have a very important influence on the growth of its early strength. With the increase of curing age, the strength difference caused by temperature will gradually increase. In the application of rebound method, the compressive strength values of concrete obtained by different strength conversion tables are very different. In this text, the strength value inferred from the national unified pumping concrete strength curve is closer to the structural strength of concrete. According to the results of this test, the cumulative maturity of concrete under the same curing condition reaching the standard curing strength of $28 \mathrm{~d}$ is $640{ }^{\circ} C \cdot d$, which needs to be corrected by further tests. In winter, concrete can be mixed with certain antifreeze, and take effective insulation measures, which is conducive to the growth of concrete strength under low temperature conditions.

\section{Acknowledgements}

The work was supported by Jinhua Science and Technology Project with the number of 2019-4-172. The authors would like to thank Jinhua Longzheng Commercial Concrete Co., Ltd and Jinhua Jinsha Commercial Concrete Co., Ltd for their financial and moral support to carry out this work. The authors also thank colleagues in Jinhua Polytechnic and Jinhua Xincheng Testing Co., Ltd for their kind help in testing and support during this project.

\section{References}

1. R. Zhu, J. Xu, Y. J. Zhan, Review on the research and application of concrete maturity theory $[\mathrm{J}]$. Concrete and cement products, 2020(10):21-26.

2. GB50204-2015, Code for quality acceptance of concrete structure construction [M]. Beijing: China Construction Industry Press.

3. Jinhua City construction project structure entity quality sampling inspection Interim Provisions [Z]. Jinhua housing and Urban Rural Development Bureau,2016.

4. R. X. Zhang, Y. M.J in,J. N. Su, et al., Experimental study on strength growth of concrete under low temperature curing [J]. Concrete,2012,05: 19-21.

5. M. K. Lin, Q .C .Wang, Experimental study on the influence of hydration degree and pore structure change of concrete on its strength under continuous low temperature [J]. Concrete,2015, (12): 4-7.

6. W. M. Wang, Development and application of concrete nondestructive testing method [J]. Architectural technology development, 2018, 45(17): 1-2.

7. S. H. Sun, X. X. Tang, Y. He, et al., Experimental study on nondestructive testing of concrete based on impact echo method in cold and dry areas [J]. Concrete, 2018(08):22-26.

8. B. Y. Xie, Experimental study on solid strength of pumping concrete in Tangshan [D]. Hebei University of technology,2005. 